\title{
Iconic Representation in Virtual Physics Labs
}

\author{
Nicole Simon* \\ Engineering/Physics/Technology Department, Nassau Community College, United States of America \\ *Corresponding author: Nicole.Simon@ncc.edu
}

\begin{abstract}
The use of imagery and iconic representation of scientific concepts is a key component in improving Critical Thinking (CT) skills while maintaining optimal Cognitive Load (CL) within higher education STEM learners. Laboratory experiences are a vital component within science education, while rote traditional lab experiments are currently not addressing inquiry nor linking with educational technologies [16]. Existing research regarding science learning using visualizations for information design processes such as underscoring vital information through cueing [3] and color coding [8], have focused on presenting a dynamic association between the integration of multiple representations with one another. Iconographic representations aid learners in comprehension as a form of intervention in learners who have a lower level of prior knowledge, while this method of assistance in higher levels of prior knowledge learners would impede further learning. Interaction design features must account for expertise reversal effect in the cognitive load schema targeting long-term memory [6,7]. By mitigating for this effect while constructing intervention processes, researcher and educators can reduce the impact on working memory through the use of carefully integrating iconic representations into learning of complex problem-solving techniques. The research performed was a causal-comparative quantitative study with 100 learners enrolled at a twoyear community college, to determine the effects of virtual laboratory experiments on CT skills and CL. Data collection involved a quantitative analysis of pre/post-laboratory experiment surveys that included a comparison using the Revised Two-Factor Study Process survey, Motivated Strategies for Learning Questionnaire, and the Scientific Attitude Inventory survey, using a Repeated Measures ANOVA test for treatment or non-treatment [17]. By studying the manner in which learners comprehend information and reducing their cognitive load while conducting scientific experiments in Virtual Learning Environments (VLEs), we are provided with the information required to structure pedagogical changes and appropriate technology resources in applicable teaching modalities [18].
\end{abstract}

\section{Keywords: educational technology, iconic representation, critical thinking}

Cite This Article: Nicole Simon, "Iconic Representation in Virtual Physics Labs." American Journal of Educational Research, vol. 3, no. 10A (2015): 1-6. doi: 10.12691/education-3-10A-1.

\section{Introduction}

Dynamic visualization, such as animations, entail intricate processes, has been found to be beneficial in the composition of laboratory schemata. Educational technology in addition to Instructional Systems Designs (ISD), have often presumed that iconic representations are advantageous when employing kinetic rather than static graphics [3]. Instructional approaches based on active discovery and problem-based learning using digital games is becoming more commonplace in today's educational forum. Opportunities to alternatively assess learning and evaluate comprehension in a digital learning environment are supportive from both a theoretical [15] perspective and an empirical research perspective [10]. Using educational games for assessment not only measures previously outlines learning objectives and goals, but allows learners to measure their cognitive load abilities in these scenarios. The purpose of this article is to review the current literature pertaining to educational game play within current curricula and the possible usages as an assessment tool within higher education.
From the perspective of both Instructional Systems Design (ISD) and educational research, the importance of game taxonomy identification in accordance with education affordances, lends themselves toward the instructing of cognitive skills. Hence, the game genre descriptors extrapolate games by virtue of the cognitive skills being employed. It has been thought by those unfamiliar with the use of games within education, that games are the educational downfall of academic-development $[1,10]$. Understanding the functionality of game usage within an educational arena, aids in empathizing how games can be beneficial to the learning process [10].

"Computer game technology is poised to make a significant impact on the way our youngsters will learn. Our youngsters are 'Digital Natives', immersed in digital technologies, especially computer games. They expect to utilize these technologies in learning contexts. This expectation, and our response as educators, may change classroom practice and inform curriculum developments" (p. 24) [10]. Multidisciplinary research has shown that the design, development, and implementation of computer games within the educational realm. Digital natives [13] were raised in digital environments that utilize computer games in everyday occurrences. According to the 
Partnership for $21^{\text {st }}$ Century Skills [11], levels of creativity and innovation skill set, in addition to communication abilities and technological literacy, were considered highly advantageous for tomorrow's learners. These skill sets could lead educators to incorporating game modification as part of future learning modalities $[1,4]$.

\section{Cognitive Load}

Cognitive Load Theory (CLT) is a theory based upon the works of Sweller [19], in that both cognition and learning are modeled through instructional design processes. In conjunction, pedagogical design and architectural design of learning instruction are coupled as to maximize the efficiency of student comprehension, while limiting the over processing capacity of acquired and learned knowledge skills. A working memory individually processes visual and auditory information as to commit these concepts to long-term memory. Sweller differentiated between intrinsic, germane, and extraneous Cognitive Load. As such, working memory has limited capacity, therefore being affected by one of the following forms of CL taxation: Intrinsic load is defined as the relationship of conceptualization to the integral complexity of the concept; Extraneous load is defined as irrelevant information based upon the design and instructional materials; and Germane load is defined as the relevant information that relations to the degree of effort that is involved in the formation of schema [9].

CLT [19] is an instructional theory that has gained credence within the field of instructional design. This branch of cognitive learning theory was implemented by Sweller during the early part of the 1980's, as a conceptualization of the framework needed to establish instructional design processes. CLT is an instructional aspect that is built upon information-processing models of learning $[9,19]$. It has been suggested [19] that severe limitations to human processing and recall capabilities exist. Most individuals compensate by "chunking" of discrete information, or grouping information into fewer pieces with larger overall units. This ability is referred to as working memory capacity. Educational games extend the working memory capacity by employing 'chunking' or scaffolding of knowledge [17]. CLT suggests that student learning is best suited for small chunking of information that may use a scaffold method, rather than overwhelming of students' cognitive resources [2]. This is based upon the notion that students having less prior information are more susceptible toward cognitive overload. One such reason may be that CLT provides the basis for multiple representations of a multi-modal learning methodology, inclusive of dual mode or an audio-visual learning environment.

The influence of preceding comprehension and cognitive engagement on the efficiency of iconic representation in science conceptualization was assessed. The existing research on learning from science conceptualization has been investigated though the use of cueing [3] and color coding [8] in an effort to demonstrated a dynamic association to and incorporation of multiple representation of learned knowledge within one another. This leads to the concept of learner control for content manipulation [8] as well as guided learning [6] for learner feedback $[17,18]$. Research has also identified prior knowledge as a significant determinant [6] of the efficiency of educational mediation.

The purpose of this quantitative quasi-experimental study was to determine how the use of iconic- representation in virtual learning environments, and how they are requisite of manipulating more than one parameter which can alter the complexity of a learning scenario. This yields an increase in cognitive load, specifically for inexperienced learners. The data revealed that the inclusion of iconic representation can enhance the learning process in inexperienced learners. This was accomplished by measuring Critical Thinking (CT) skills, and Cognitive Load (CL) among learner participants at a two-year community college. The predetermined instruments include: the Scientific Attitude Inventory (SAI II) [8], and the Revised Two-Factor Study Process Questionnaire (RSPQ-2F) $[17,18]$. The statistical analysis was conducted as to explore the relationships between use of inquiry-based simulated and virtual laboratory experiments and learner perceived increases in Critical Thinking Skills, and Cognitive Load ability. The intention of this study was to investigate the increases of CT skills in labs utilizing iconic representation. This study served to identify which course instructional delivery method will attain: perceived increased CT skills, and increase CL capability within iconic-based laboratory science experiments.

The learners were separated into two pre-existing groups based on random selection of course section. The analysis was aimed at comparing laboratory format pre/post-lab surveys with learner perceived increases in Critical Thinking Skills (dependent variable), and Cognitive Load (dependent variable) with respect to the two learner groups being treated or controlled (independent variable) controlling for the mathematical and scientific backgrounds of the learners (covariate) and the possible effects of computer usage skills will performing the laboratory experiments (covariate).

The Force Table experiment describes the relationship between vectors and vector analysis. The version of the simulation presented in Figure 1 uses icons to represent the vector components, which are essential to the learning process. While Figure 2 depicts an animation without iconic representation. A distinction exists between iconic and symbolic representation of phenomena that is based upon taxonomic representations that amplify in their intricacy and generalization. Homer and Plass [6] noted that a progressive development between learning contextual usage of terms based upon pictorial representation and abstract meanings used in vernacular culture. These icons were integrated into the simulation to assist beginner physics learners ascertain the visual representation of the simulation by offsetting their lack of domain-specific topical antecedent comprehension. Past research has demonstrated that the inclusion of said icons in scientific simulations can aid in the reduction of cognitive load, specifically for those learners with low prior knowledge of topical material [6].

\section{Methodology}

The purpose of this quantitative quasi-experimental study was to determine how the use of iconic 
representation in virtual science laboratory experiments increase learner CT skills and CL among learner participants at a two-year community college. The predetermined instruments include: the Scientific Attitude Inventory (SAI II) and the Revised Two-Factor Study Process Questionnaire (R-SPQ-2F). The statistical analysis was conducted as to explore the relationships between use of iconic representation and increases in CT Skills and CL ability. This study served to identify which course instructional delivery method will attain: perceived increased CT skills, and increase CL capability within virtual laboratory science experiments either utilizing iconic representation or omitting this depiction.

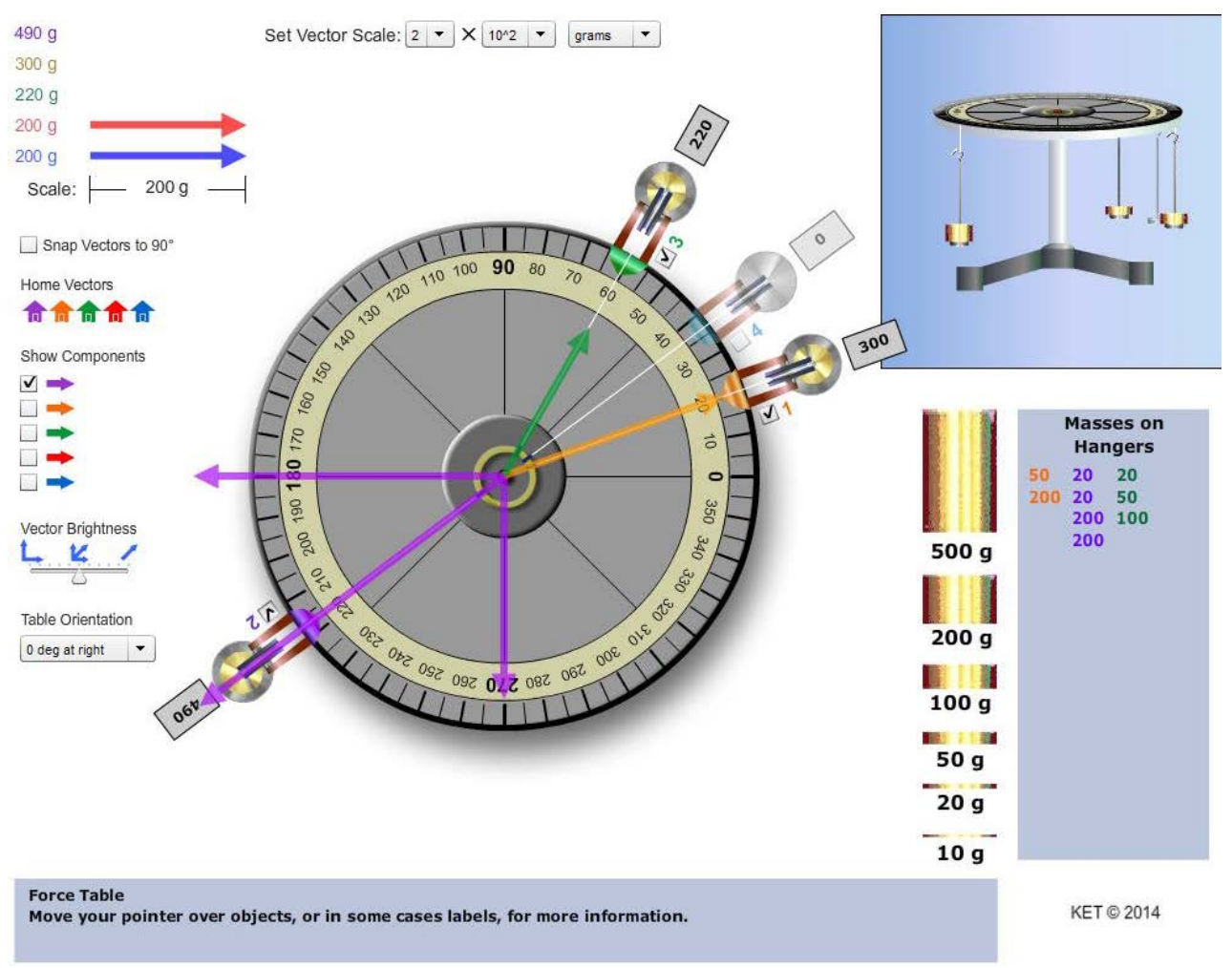

Figure 1. Force Table narrated visualization with iconic representation (provided by KET Virtual Labs)

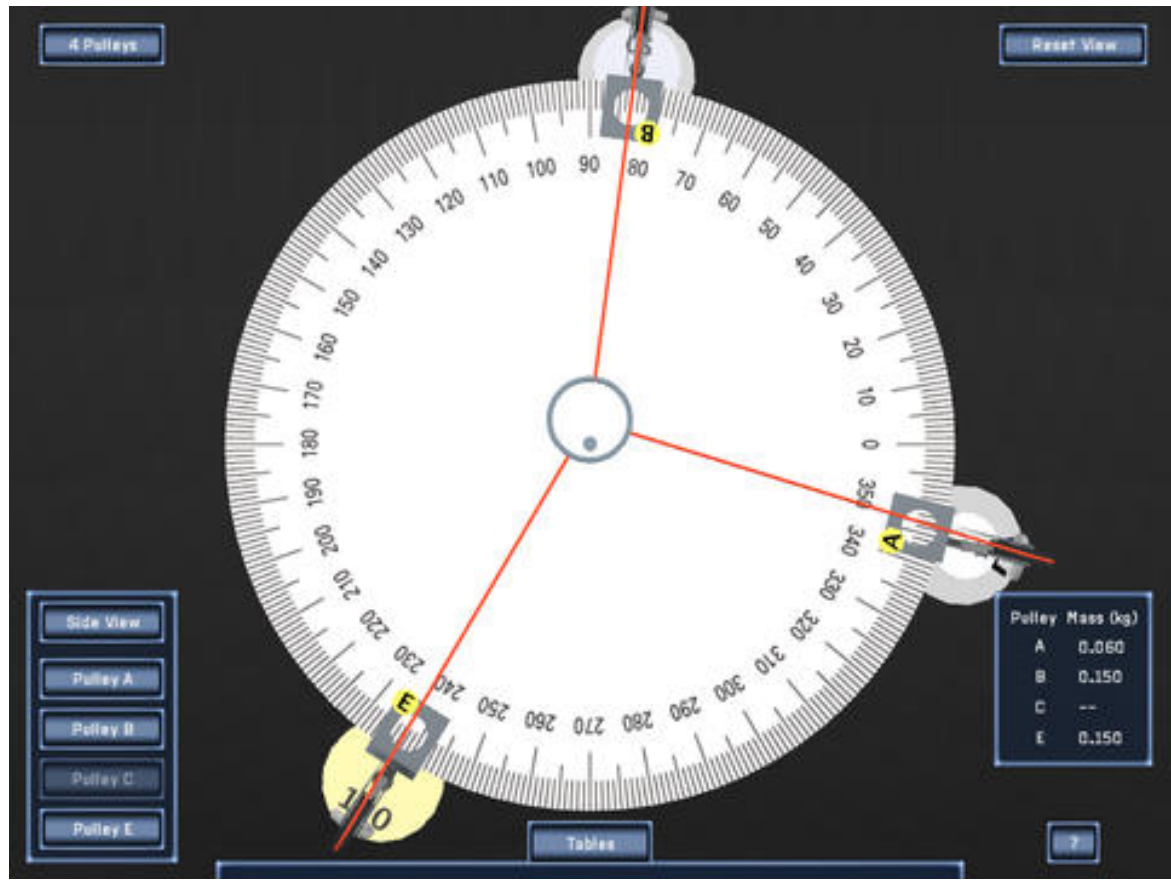

Figure 2. Force Table narrated visualization with-out iconic representation (provided by Polyhedron Labs)

The learners were separated into two pre-existing groups based on random selection of course section. All learners had the same academic background in both mathematics and science from high school. The analysis was aimed at comparing icon experiment treatment to non-icon experiment treatment as to measure both CT skills and CL ability for the purpose of creating new laboratory experiments that raise each variable level for future learners. 
The surveys were administered at the beginning and at the mid-point of the course, and it will determine how learners perceive an improvement or increase in their science abilities due to completing the course laboratory experiments. The rationale for administering the post-lab survey at the mid-point of the course is based on attrition rates for non-majors in the STEM laboratory courses. By surveying at mid-semester, the researcher had a more heterogeneous participant population. Whereas at the end of the semester, the population would be more homogenous consisting of the academically stronger students, thus biasing the data by showing an unequal mix of learners throughout the course.

\section{Results}

The results of the presented study are based on data collected during an academic year. A total of 100 learners participated in the study. Each learner provided informed consent to the collection of this data. All data are anonymized as to avoid any personally identifiable information.

\subsection{Critical Thinking}

Critical Thinking (CT) skills were assessed as to the extent in which they differed for learners exposed to iconic representation during visualization of the Force Table than those with no treatment. Results of the statistical analysis of the repeated measures indicated that the use of icons had some effect on the learning process. The results indicated that the iconic representation in the treatment group does increase the use of CT Skills. The use of CT Skills with icons consisted of two main subscales, deep learning and surface learning. The results showed that learners in the treatment (icon experiment modalities) group had higher levels of CT Skill usage and implementation (as measured by the R-SPQ-2F survey) than learners in the non-treatment (non-icon experiment modalities) group.

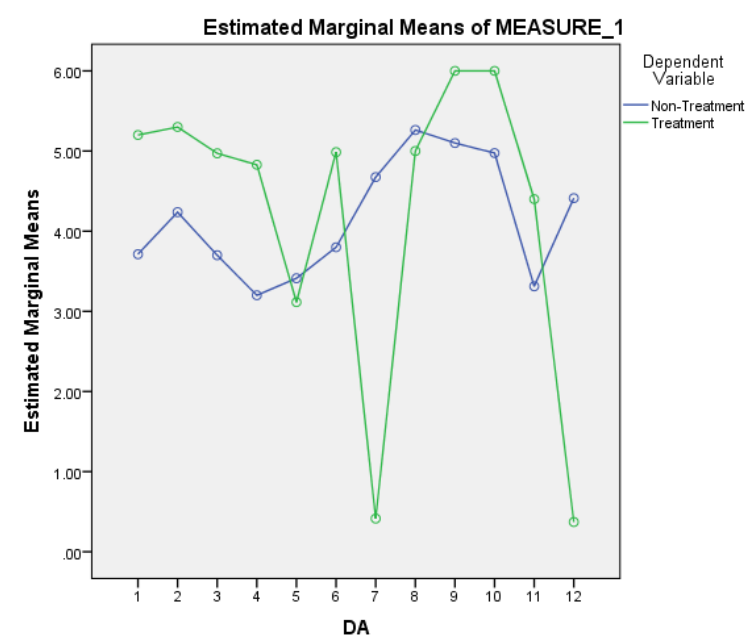

Figure 3. Estimated Marginal Means (Pre/Post-lab) R-SPQ-2F Deep Approach Subscales Comparison of Critical Thinking Skills for IconicRepresentation

The estimated marginal means data (as shown in Figure 3) shows that the treatment group increased their CT Skills post-experiment.
The graph of estimated marginal means represented a comparison of unequal sample sizes between the treatment group and the non-treatment group. The relationship between the dependent variables depicted a computed average across the levels of within and between subject factors. The graph displays an interaction of the variables pertaining to the usage of virtual and simulated science labs' effect on Critical Thinking Skills as it relates to deeper levels of learning. The levels of learning, both deep and surface level approaches, correspond to the treatment and non-treatment groups respectively.

The findings from this research are that those learners in the treatment group thought more critically and analytically than learners in the non-treatment group, is consistent with past research on the usage of iconic representation in science laboratory experiments $[6,7,12]$. The results are significant in that they indicate the use of CT Skills in a deep and surface learning capacity. The research findings denoted that learners are using more indepth methods for scientific analysis through the use of Critical Thinking. The inclusion of critical thinking, within experimentation, is evident that the progression of synthesis and evaluation of learner material is ongoing $[6,7,18]$. Furthermore, deep and surface learning strategies were employed more often and in more substantial form from the treatment modality than from the non-treatment modality. The data showed that this was not the case, based on the R-SPQ-2F ANOVA results that indicated learner depth of knowledge was higher than anticipated in the treatment group.

The findings from this research are that those learners in the treatment group thought more critically and analytically than learners in the non-treatment group, is consistent with past research on the usage of iconic representation in laboratory experiments within the science disciplines $[7,8,9]$. There are three components integral in science education within the domain of higherorder cognitive skills development include: problemsolving, Critical Thinking, and laboratory practice. The results are significant in that they indicate the use of CT Skills in a deep and surface learning capacity. The research findings denoted that learners are using more indepth methods for scientific analysis through the use of Critical Thinking. The inclusion of critical thinking, within experimentation, is evident that the progression of synthesis and evaluation of learner material is ongoing [6]. Furthermore, deep and surface learning strategies were employed more often and in more substantial form from the treatment modality than from the non-treatment modality. The data showed that this was not the case, based on the R-SPQ-2F ANOVA results that indicated learner depth of knowledge was higher than anticipated in the treatment group.

\subsection{Cognitive Load}

Cognitive Load (CL) capacity was assessed as to the extent in which they differed between the use of iconic representation in laboratory experiments when compared pre- and post-laboratory experiments. Results of the statistical analysis of the repeated measures indicated that the use of the icons in the treatment group does not statistically show great significance in the Cognitive Load. The effective use of Cognitive Load with icons is 
marginally reduced and therefore, somewhat significant, as the within groups showed more efficient use of working memory than that of the between group results. The results showed that learners in the treatment group had moderately higher levels of Cognitive Load usage and implementation (as measured by the SAI-II survey) than learners in the non-treatment group. The findings from this research are that those learners in the treatment group used similar levels cognitive load capabilities as did learners in the non-treatment group, is consistent with past research on the usage of iconic representation in laboratory experiments within the science disciplines $[4,6,17,18]$.

\section{Summary and Conclusion}

In this paper, the impact of iconic representation in science laboratory experiments, on learning developing, Critical Thinking (CT) skills and Cognitive Load (CL) capabilities, is studied. A pre/post survey methodology is introduced, as to distinguish learning events during laboratory experimentation. Statistical results are presented that show Critical Thinking Skills can be achieved as well as increased Cognitive Load ability in iconic-based laboratory learning environments. With the incorporation of these learning environments into General Science Study laboratory courses, learners may increase their knowledge base within defined course content areas more expressly directed at the science disciplines. The research study showed that, when utilized properly, simulation software and virtual laboratory experiments can facilitate an environment for learning that develops and fosters Critical Thinking and Cognitive Load gains. These variables will help to maintain or exceed Cognitive Load abilities; explicitly aimed at the scientific disciplines, scientific technology, and overall scientific awareness. Instructional and educational design of a course aids in the determination of whether a learner utilizes deep or surface learning through Critical Thinking and Cognitive Load abilities [19]. Educators need to heed the use of simulations and virtual laboratory experiments in science courses so that their uses are based upon sound instructional theories and best practices $[6,18,19]$.

This study offered a discrete perspective for science educators with interests in simulation and virtual laboratory experiments and for educational technologists interested in creating these learning environments. Therefore, it is recommended that science educators and educational technology specialists in higher education fully examine the effectiveness of iconic representation in simulation laboratory experiments in science education. The requirements for learners in General Science Study laboratory courses is to master scientific concepts and engage in meaningful knowledge through learning approaches that can be used for a multitude of educational and career pathways. For the reason that many of these laboratory experiments will never be used by non-science major learners in their academic futures, the results of this research study may support the use of the educational technology instructional methodologies that are not "wet" laboratory based. The current research findings support the use of simulations and virtual laboratory experiment software in science laboratory experiments as long as science educators use the educational technology in a proper manner when designing and implementing instructional design planning for curricula. The results of this study will allow educators to identify that simulations and virtual laboratory experiments play an integral role in science education. Educational technology will only enhance the learning experience, not distract from the outcomes of the science curricula.

\section{References}

[1] Bartholow, B. D., Sestir, M. A., \& Davis, E. B. (2005). Correlates and consequences of exposure to video game violence: hostile personality, empathy, and aggressive behavior. Personality and Social Psychology Bulletin, 31(11), 1573-1586.

[2] Cook, M. (2006). Visual representations in science education: The influence of prior knowledge and Cognitive Load on instructional design principles. Science Education, 90(6): 1079-1091.

[3] de Koning, B., Tabbers, H., Rikers, R., \& Paas, F. (2007). Attention cueing as a means to enhance learning from an animation. Applied Cognitive Psychology, 21, 731-746.

[4] Gee, J. (2008). Game-like learning: An example of situated learning and implications for opportunity to learn. In P. A. Moss, D. C. Pullin, J. P. Gee, E. H. Haertel, \& L. J. Young (Eds.), Assessment, equity, and opportunity to learn (pp. 200-221). New York, NY: Cambridge University Press.

[5] Hasler, B., Kersten, B., \& Sweller, J. (2007). Learner control, cognitive load and instructional animation. Applied Cognitive Psychology, 21, 713-729.

[6] Homer, B., \& Plass, J. (2010). Expertise reversal for iconic representations in science simulations. Instructional Science, 38, 259-276.

[7] Kalyuga, S., \& Plass, J. (2007). Managing Cognitive Load in Instructional Simulations. In M. Nunes \& M. McPherson (Eds.), Proceedings of the IADIS International Conference e-Learning 2007, 27-34. Lisbon, Portugal.

[8] Keller, T., Gerjets, P.; Scheiter, K., \& Garsoffky, B. (2006). Information visualizations for knowledge acquisition: The impact of dimensionality and color coding. Computers in Human Behavior, 22(1), 43-65.

[9] Moss, D. C. \& Azevedo, R. (2006). The role of goal structure in undergraduates' use of self-regulatory processes in two hypermedia learning tasks. Journal of Educational Multimedia and Hypermedia, 15, 49-86.

[10] O’Brien, D., Lawless, K., \& Schrader, P. (2010). A Taxonomy of Educational Games. In Y. Baek (Ed.), Gaming for ClassroomBased Learning: Digital Role-Playing as a Motivator of Study, 123, Hershey, PA: IGI Global.

[11] Partnership for 21st Century Skills. (2006). Results that matter: 21st century skills and high school reform. Tucson, AZ: Partnership for $21^{\text {st }}$ Century Skills.

[12] Plass, J.L., Homer, B.D., Milne, C., Jordan, T., Kalyuga, S., Kim, M., \& Lee, H.J. (2009). Design Factors for Effective Science Simulations: Representation of Information. International Journal of Gaming and Computer-Mediated Simulations, 1(1), 16-35.

[13] Prensky, M. (2001). Digital natives, digital immigrants. Horizon, 9(5). http://www.marcprensky.com/writing/Prensky\%20\%20Digital\%20Natives, \% 20Digital\%20Immigrants\%20\%20Part1.pdf. Retrieved September 26, 2014.

[14] Prensky, M. (2008). Students as designers and creators of educational computer games: Who else? British Journal of Educational Technology, 39(6), 1004-1019.

[15] Price, C., \& Moore, J. (2010). The Design and Development of Educational Immersive Environments: From Theory to Classroom Deployment in Gaming for Classroom-Based Learning. Ed Young Baek. ICI Global.

[16] Pyatt, K., \& Sims, R. (2011). Virtual and physical experimentation in inquiry-based science labs: Attitudes, performance, and access. Journal of Science Educational Technology.

[17] Simon, N. (2014). Simulated and Virtual Science Laboratory Experiments: Improving Critical Thinking and Higher-Order Learning Skills. In M. Searson \& M. Ochoa (Eds.), Proceedings of Society for Information Technology \& Teacher Education International Conference 2014, 453-459. Chesapeake, VA: AACE. 
[18] Simon, N. (2015). Improving Higher-Order Learning and Critical Thinking Skills using Virtual and Simulated Science Laboratory Experiments. In K. Elleithy \& T. Sobh (Eds.), New Trends in Networking, Computing, E-learning, Systems Sciences, and Engineering, 312, 187-192.
[19] Sweller, J. (2005). Implications of Cognitive Load theory for multimedia learning. In R. E. Mayer (Ed.). The Cambridge handbook of multimedia learning. New York, NY: Cambridge University Press. 